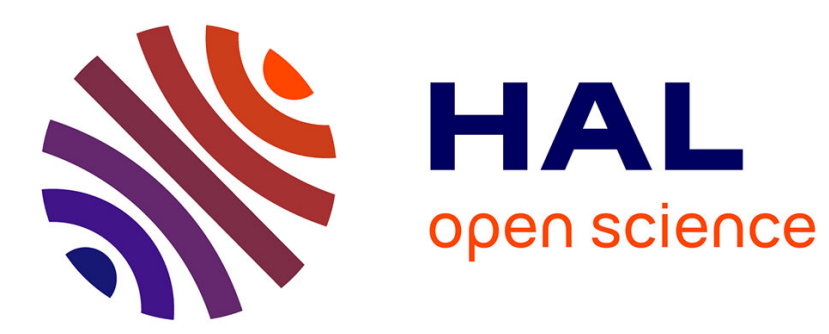

\title{
Mucopolysaccharidoses seen in adults in Rheumatology
}

Stéphane Mitrovic, Hélène Gouze, Laure Gossec, Thierry Schaeverbeke, Bruno

Fautrel

\section{To cite this version:}

Stéphane Mitrovic, Hélène Gouze, Laure Gossec, Thierry Schaeverbeke, Bruno Fautrel. Mucopolysaccharidoses seen in adults in Rheumatology. Joint Bone Spine, 2017, 10.1016/j.jbspin.2017.01.008 . hal-01474723

\section{HAL Id: hal-01474723 \\ https://hal.sorbonne-universite.fr/hal-01474723}

Submitted on 23 Feb 2017

HAL is a multi-disciplinary open access archive for the deposit and dissemination of scientific research documents, whether they are published or not. The documents may come from teaching and research institutions in France or abroad, or from public or private research centers.
L'archive ouverte pluridisciplinaire HAL, est destinée au dépôt et à la diffusion de documents scientifiques de niveau recherche, publiés ou non, émanant des établissements d'enseignement et de recherche français ou étrangers, des laboratoires publics ou privés. 


\section{Mucopolysaccharidoses seen in adults in Rheumatology}

Stéphane Mitrovic ${ }^{1,2, *}$, Hélène Gouze ${ }^{1,2, *}$, Laure Gossec $^{1,2}$, Thierry Schaeverbeke ${ }^{3}$, Bruno Fautrel ${ }^{1,2}$

* Stéphane Mitrovic and Hélène Gouze contributed equally to this review

UPMC University Paris 06, Institut Pierre Louis d'Epidémiologie et de Santé Publique, GRCUPMC 08 (EEMOIS), ${ }^{1}$ Sorbonne Universités, 75005 Paris, France

${ }^{2}$ Department of rheumatology, AP-HP, Pitié Salpêtrière Hospital, 75013 Paris, France

${ }^{3}$ Department of Rheumatology, Pellegrin Hospital, Bordeaux University Hospital, 33076 Bordeaux, France

Corresponding author: Stéphane Mitrovic, Hôpital Pitié-Salpêtrière, Service de Rhumatologie, 47-83, boulevard de l'Hôpital - 75013 Paris France.

Mail: stephane.mitrovic@aphp.fr

Tel: +33142178421 Fax: +33142177959 


\begin{abstract}
Mucopolysaccharidoses are a group of rare lysosomal storage diseases including a great number of polymorph syndromes, each being related to a particular mutation responsible for a deficiency of glycosaminoglycan degrading enzymes, leading to an accumulation of glycosaminoglycans in tissues. Many of them are diagnosed in children or teenagers and have a severe prognosis because of organ failure, and are consequently usually not seen by the adult rheumatologist. However, some of them have a more progressive presentation, with musculoskeletal symptoms at the forefront and a lifespan that nearly reaches that of the general population. These milder forms are more likely to be diagnosed in adults, in patients who have suffered for years and sometimes even decades with unrecognized mucopolysaccharidosis. Indeed, they can sometimes mimic inflammatory rheumatic disorders, and therefore be misdiagnosed for a long time. Recognition and diagnosis of these attenuated forms can be a real challenge as they lead to moderate and/or nonspecific symptoms such as joint pain or stiffness. Hence, rheumatologists should know about them. Early diagnostic is essential since specific treatment, like enzyme replacement therapy, is now available for some subtypes and might, if given early, slow down the development of tissue damage, which is unfortunately irreversible. This article provides the opportunity to review the main clinical and radiographic features, the diagnostic strategy and the update of management, which should be multidisciplinary and led by an experienced physician in a reference centre. The contribution of the rheumatologist is important to ensure symptom control and prevent complications.
\end{abstract}

Keywords: mucopolysaccharidoses, lysosomal storage diseases, joint contractures, spondyloepiphyseal dysplasia, rare diseases, enzyme replacement therapy 


\section{Introduction}

Mucopolysaccharidoses (MPS) are a group of rare lysosomal storage diseases including a great number of polymorph syndromes (1). Most of them are diagnosed in children or teenagers and have a severe prognosis because of organ failure, and are consequently usually not seen by the adult rheumatologist $(1,2)$. However, some of them have a mild and more slowly progressive presentation, with osteoarticular symptoms at the forefront and with a lifespan that nearly reaches that of the general population (3). These milder forms are more likely to be diagnosed in adults, in patients who have suffered for years and sometimes even decades with unrecognized MPS $(4,5)$. Indeed, they can sometimes mimic inflammatory rheumatic disorders, and therefore be misdiagnosed for a long time. Hence, rheumatologists should know about their existence and be able to make the diagnosis as soon as possible, since specific treatment like enzyme replacement therapy or stem cell transplantation are now available and might, if given early, stop or slow the development of tissue damage, which is unfortunately irreversible (6).

\section{Physiopathology and classification}

MPS are mostly autosomal recessive, and represent a heterogeneous group of lysosomal storage diseases including a huge number of polymorph syndromes, each being related to a particular mutation (Table 1). These mutations are responsible for a deficiency of glycosaminoglycan (GAG) degrading enzymes, leading to an accumulation of GAGs in tissues generating impairment. The multiplicity of the enzymes involved in GAGs catabolism, and of the possible mutations and deficiency, account for the numerous subtypes of MPS, but also for the great clinical heterogeneity and various phenotypes inside each subtype, from severe infantile multivisceral diseases to milder musculoskeletal symptoms-prevailing forms of later diagnostic.

GAGs are linear sulfated chains which can associate with a protein in order to form proteoglycans that are involved in almost all tissues of the organism. Lysosomal enzymes normally insure the degradation of GAGs. Hence, the deficiency of an enzyme implied in GAG catabolism will lead to GAG storage that will disturb cellular, tissue and organ homeostasis, through alteration of complex multifarious pathways. GAGs are no longer considered just as inert substrates accumulating in tissues, but are biologically active molecules involved in many critical cellular and tissue pathways, including signal transduction, sequestration of extracellular humoral factors and modulation of the cross talk between cells $(7,8)$. Although all the mechanisms are not fully 
understood, it seems that GAGs accumulation provokes secondary events through a series of metabolic, inflammatory and immunological responses, in bone and cartilage (8) but also connective tissues (7), via mechanisms such as Toll-Like Receptor 4 (TLR4) activation (9), or increased nitric oxide and inflammatory cytokine release (10). Of capital importance, once initiated secondary consequences of GAG storage can be irreversible, which underscores the critical importance of intervention with enzyme replacement therapy early in the course of the disease, in order to improve long-term outcome (7). The joint symptomatology in each of the MPS results from both primary effects of the disease on articular cartilage and the surrounding connective tissue structures, as well as primary bone disease $(7,11,12)$ (Table 2). GAG storage and its consequences also affect almost all the connective tissues, accounting for the potential multisystemic clinical manifestations.

\section{Epidemiology}

Owing to the rarity and clinical heterogeneity of the disease, it is very difficult to know precisely MPS epidemiology (Table 1). The overall combined incidence of mucopolysaccharidoses is comprised, according to the countries, between $\sim 1$ for 16000 and $\sim 1 / 29000$ live births (13-16). The prevalence of all MPS reported in Scandinavian countries varies from 4 to 7 per 1000000 inhabitants in 2007 (17). MPS I is the most frequent type with an incidence between 0.69 and 1.66 for 100000 newborns (18). MPS IV A point prevalence varies from 1 per 323000 in Denmark to 1 per 640000 inhabitants in Australia, but all these results are compromised by poor study reporting and internal validity. Of note, the parents are consanguineous in up to $20 \%$ of cases of MPS IV A (19). However, MPS are certainly underdiagnosed due to health-care professionals' lack of awareness, to poor access to screening and diagnostic methods, and to their extensive clinical heterogeneity (14). A recent survey of 60 adult and paediatric rheumatologists in North America and Europe found that $\sim 80 \%$ were unable to recognize symptoms of MPS I and did not know the appropriate diagnostic tests (20). Attenuated more progressive forms may also occur, which can make diagnosis even more difficult. A recent study reported that a systematic screening for MPS in a sample of rheumatology and orthopaedic patients with joint complaints of unknown aetiology would identify 1 case out of 55 patients (14). 


\section{Clinical characteristics}

\subsection{Great clinical heterogeneity}

A key message is that there is no specific symptom of MPS, which present a great clinical heterogeneity. Each patient is unique, and the age of symptom onset, the order of symptom apparition, the severity and evolution will vary, offering a continuum of clinical expressions: from severe forms leading to premature death in childhood (mainly because of visceral complications) to mild attenuated forms with quasi normal lifespan (21). Recognition and diagnosis of these attenuated forms can be a real challenge because they lead to subtle and/or nonspecific symptoms, and the diagnosis is thus often made much later in life during adulthood (14). Hence, this implies the need for adult rheumatologists to be prepared to recognize and diagnose MPS.

\subsection{Musculoskeletal manifestations}

Despite the great heterogeneity of clinical features and severity, musculoskeletal involvement is a common feature in all types (22). Symptoms are various (Table 3) since bone, cartilage, ligaments and all the soft tissues may be impaired by GAG infiltration $(12,22-24)$. The date of apparition of symptoms may vary, but an onset at early age is suggestive. The most common rheumatologic features are development of joint pain and joint contractures without concomitant inflammation (1). Osteochondrodysplasia, due to abnormal enchondral ossification, is the most characteristic bony manifestation.

Joint stiffness and contractures can be found in all type of MPS, except for MPS IV and MPS IX (25), and affect all joint type. Physical examination often shows articular limitation in extension, whereas flexion is more likely to be preserved. In the hand, joint stiffness preferentially affects the phalangeal joints, although all joints can be affected. When the interphalangeal joints of the hands are affected, a characteristic claw hand deformity may develop, often resulting in impaired hand function (22). If the stiffness and contractures may mimic rheumatic conditions (such as rheumatoid arthritis (RA), juvenile idiopathic arthritis (JIA) or psoriatic arthritis) (22), there are however several important differences (25): the pain rhythm is not typically inflammatory (i.e. stiffness worse in the morning and relieved by activity), local signs of inflammation (such as warmth, swelling and tenderness) are lacking, and so are systemic signs of inflammation such as fever and/or elevated acute phase reactants. Finally, there is no response to steroids, but nonsteroidal anti-inflammatory drugs may sometimes relieve some symptoms. Some joints may have a swollen appearance due to underlying bony enlargement, and/or to a clinical entity reported by several authors, named chondrodysplasic rheumatism, where patients with epyphyseal dysplasia 
present acute "osteoarthritic-like" exacerbations with swollen joints and synovitis, but with mechanic synovial fluid and without any elevation of acute phase reactants $(26,27)$ (Figure 1). The phalangeal contractures observed in MPS may also mimic the contractures seen in camptodactyly or diabetic cheiroarthropathy. Skin tightening and thickening might accompany the contracture, and resemble the skin changes of scleroderma (22). When stiffness and contractures involve the ankles and Achilles tendons, patients may present with toe-walking (22).

In contrast with most types of MPS, where joint stiffness is characteristic, most patients with Morquio syndrome (MPS IV) have joint hypermobility caused by metaphyseal deformity, bone hypoplasia and degradation of connective tissue around the joint (21). Most patients have significant joint hypermobility of the distal joints contrasting with proximal stiffness, the result being a waddling gait (21). The distal hypermobility often results in a very weak grip and progressive difficulty with activities of daily living, including dressing and personal care (22).

Carpal tunnel syndrome and other entrapment neuropathy are very frequent in MPS, up to $50 \%$ of patients (2). Median nerve compression occurs as a result of thickening of the flexor retinaculum and the tissues around the tendon sheaths (2). Trigger digits are another very common feature of MPS. If carpal tunnel syndrome and trigger fingers are frequent in the healthy adult population and may seem ordinary, the physician should however be particularly careful in front of these pathologies occurring in children or young adults. Furthermore, the association of these two pathologies in the same patient is well recognized as a characteristic of patients with an MPS (2).

Dysmorphic features are suggestive but not pathognomonic, and include: brevity of the neck and thorax, thoracic deformation with protrusion of the sternum, kyphoscoliosis, spondyloepiphyseal dysplasia, flessum of the hip, genu valgum, flat feet (Figure 1). If growth abnormalities leading to dwarfism or short stature are frequent in severe paediatric forms, the patients with attenuated forms of MPS however may have normal or near-normal linear growth (22). Dysostosis multiplex is the term used to describe the group of skeletal abnormalities and radiographic changes characteristic of MPS (22). Radiographs show characteristic vertebral abnormalities with early anterior hypoplasia of T12, L1 or L2, which is visible as anterior vertebral beaking and is often responsible for thoraco-lumbar kyphosis. The vertebral abnormalities worsen over time, eventually leading to diffuse flattening of the vertebrae and widening of the intervertebral spaces, which will lead to the classical aspect of platyspondylia on the radiographs (Figure 1). Scoliosis and spondylolisthesis, although not specific of MPS, are often associated. Hypoplasia of the dens, cervical stenosis and instability are common and severe manifestations (mainly of MPS IV, VI and to a lesser extent I) that may lead to atlanto-axial instability, compression of the cervical spinal cord, and complications during endotracheal intubation. Changes in the lower extremities include dysplastic femoral heads (favored by underdevelopment of the 
proximal femoral epiphysis), flattened acetabula, hypoplasia of the inferior portions of the iliac bones with flared iliac wings, coxa valga or vara, genu valgum deformities (up to 50\% of the patients) (2). Epiphyseal dysplasia can also occur in interphalangeal joints of hands and feet. Finally, osteopenia is also a common feature, but seems to be more frequent in MPS VI and VII.

\subsection{General manifestations and evolution}

The general clinical manifestations of MPS are polymorph and may include facial dysmorphia, organomegaly and manifestations related to visceral failure, mainly neurologic, cardiologic and ophthalmologic (Table 3) (1,2, 28-30). They are not always present accord to the subtype, especially in milder progressive forms, but should be always sought.

Lifespan is influenced by the severity of the phenotype and especially the presence or absence of visceral injuries: if rapidly progressing paediatric variants experience death during childhood or adolescence, lifespan might be almost normal in attenuated forms. However, overall lifespan has been gradually improving over the past decades, thanks to progresses in earlier recognition of patients with slower disease progression, advances in supportive multidisciplinary care and the development for some type of disease specific treatments (31).

\section{Differential diagnoses}

Differential diagnoses are numerous and MPS are often misdiagnosed (Table 4). MPS are part of a larger class of diseases, the lysosomal storage diseases that all share common clinical features $(32,33)$. However, MPS are much more often misdiagnosed as rheumatic inflammatory disorders by adult rheumatologists: RA (or JIA if early onset), psoriatic arthritis and sometimes spondylarthritis according to the symptoms. Muskuloskeletal and skin manifestations can be confounded with connective tissue disease like scleroderma or poly/dermatomyositis. Osteochondrodysplasias can be a manifestation of MPS, but not all dysplasias result from LSDs, and many spondyloepiphyseal or spondylometaphyseal dysplasias can be observed independently, or in link with another underlying disease. However, in front of diffuse dysplasia, the physician should raise the possibility of an underlying MPS, and if necessary investigate further. Furthermore, the adult rheumatologist should be particularly attentive to the medical past history of the patient, especially to diseases or symptoms diagnosed in childhood, such as "growing pains" or primary osteochondritis (also called Legg-Perthes-Calvé disease). This latter can induce secondary hip 
dysplasia in children, is often bilateral (10\% of cases) and familial (6\% of cases) (34), and can be confounded with the hip dysplasia found in MPS.

\section{Diagnosis}

\subsection{Diagnostic algorithm}

Diagnoses of these disorders can be complex, and that's why a diagnostic algorithm can be of help (Figure 2). When an MPS is suspected, the patient should be referred to a geneticist or metabolic specialist in a reference centre for laboratory testing (www.orphanet.org). Indeed, besides the great complexity of the assays, there are potential diagnostic pitfalls that should be avoided. An MPS diagnosis is based on laboratory results from urinary GAG analyses (quantitative and qualitative GAG assays), which act as screening guiding tests, that should secondary be confirmed by enzyme activity assays that measure enzyme activity in tissues (blood leukocytes or fibroblasts).

\subsection{Orientation screening tests: urine GAG analyses}

Quantitative assays measure overall elevation of GAG in the urine, as compared with GAG levels expected in age-matched normal subjects (1). Qualitative assays (such as GAG electrophoresis) detect the type of GAG excreted. In children, adolescents and young adults, most MPS patients have higher GAG excretion in urine, compared with age-matched normal subjects. However, urinary GAG excretion varies with age, higher values being found during the first years of life, followed by a slow and constant decrease thereafter (1). Hence, not all MPS patients have a clear elevation of total GAG excretion, especially in adults with milder and more progressive forms. That's why an accurate diagnosis requires a full GAG profile, including both quantitative and qualitative analysis done in tandem $(35,36)$. In fact, patients with different types of MPS differ not only in the total amount of GAG excreted in urine, but also in the relative proportion of various type of GAG, leading to a particular abnormal pattern for each MPS subtype (37): the presence of specific GAGs can suggest the MPS subtype and may direct the appropriate enzyme analyses (Table 1). For example, high amounts of heparan sulfate or keratan sulfate essentially characterize MPS III and IV, respectively. Besides the age or the severity of the disease phenotype (1), other factors, such as heparin (that interferes with the assays) or inappropriate sample storage, can influence GAG excretion and provide false negatives. Thus, an MPS diagnosis should neither be confirmed nor ruled out on the basis of a single urine GAG test (although it is usually the first step in the diagnostic pathway), but confirmed by enzyme activity testing. 
A new technique for evaluation of urinary excretion of GAG based on a multiplex tandem technique using both chromatography and mass spectrometry, is in development and seems promising, but requires further testing and validation (38).

\subsection{Biologic confirmation test: enzyme activity measurement in plasmatic leukocytes}

The diagnosis of MPS should be confirmed by enzyme activity testing. Enzyme activity is typically measured in plasmatic leukocytes (1). Some laboratories might also still measure enzyme activity in cultured fibroblasts, although skin biopsy is more invasive than blood sampling. A new technique of measuring enzyme activity from dried blood spot (DBS) has been proposed for many types of MPS $(1,39)$. DBS-based assays offer considerable practical advantages with respect to sample collection, storage and transport, and multiple enzyme activity tests can be performed on a single DBS. However, although sensitivity and specificity seem correct if appropriate controls are performed, false negatives can occur, it is still recommended that a positive result from a DBS be confirmed by a tissue-based assay (1). Hence, measurement of enzyme activity in plasmatic leukocytes remains the gold standard.

\subsection{Predicting disease severity and evolution}

Once the enzyme deficiency is confirmed, predicting disease severity remains difficult. Urinary GAG level cannot be utilized as a reliable indicator of severity, especially in adults (18). Genotype-phenotype correlations have been limited by the rarity of the disorders and the large number of mutations, many of which occur only in a single affected family (18). Mutation analysis or molecular testing includes looking for the known disease-causing mutations in addition to looking for abnormal sequences in the gene coding for a particular enzyme. Molecular testing can have prognostic value if the mutations that are identified have been characterized $(40,41)$. When a patient has been diagnosed with a specific type of MPS and his/her mutation is known, the information can be used for carrier testing and prenatal testing of siblings $(1,42)$. It is important to note that except for MPS II (Hunter), the MPS are inherited in autosomal recessive fashion, so carriers have a very small likelihood of having children affected with MPS unless the union is consanguineous (1).

\section{Treatment}


MPS should be managed by a multidisciplinary team coordinated by a physician with experience in the treatment of these complex disorders, ideally in a reference centre (43). When available, a disease-specific treatment should be started as early as possible; supportive treatments are always important. The main therapeutic goals are: to improve or slow down (if possible) the systemic evolution of the disease, to improve the quality of life and socio-professional insertion, and to provide clear information about the disease and complications (44). Regular follow-up is essential to monitor disease progression and response to treatment (43).

\subsection{Disease-specific treatments}

The rationale is to provide the patient with active enzyme to replace the enzyme that is deficient, either exogenously through enzyme replacement therapy (ERT), or endogenously through haematopoietic stem cell transplantation (HSCT) in infants (43). Disease-specific treatments are not curative, but can improve outcome (prevention, stabilization, retardation of disease progression, in addition to improvements in clinical status) and quality of life. Due to the progressive nature of the disease, response to any form of treatment is influenced by the severity of the disease phenotype and the degree of disease progression at treatment initiation (43). Hence, ERT is most effective when started early in life, before the development of irreversible damage $(18,31,45,46)$. Limited data exist on the effects of ERT when started in adulthood and more research is warranted to fill this evidence gap.

\subsubsection{Enzyme replacement therapy}

ERT is currently available for MPS I, II, IVA and VI, and clinical trials for MPS VII and MPS IIIA are ongoing $(47,48)$ (Table 1). ERT has been shown to have favourable effects on urinary GAG levels, endurance, respiratory function, range of joint motion, hepatomegaly, growth (height) and cardiac function $(43,49-53)$. Influence of ERT on the quality of life has not been evaluated in dedicated studies but has been punctually described in the therapeutic trials and seems to have a positive impact on activities of daily living, pain and Health-related quality of life scores $(49,54)$.

\subsubsection{Haematopoietic stem cell transplantation}

HSCT is considered the standard of care in infants with severe MPS, associated with neurocognitive impairment, due to the inability of intravenously infused ERT to pass the blood-brain barrier $(31,43,55)$. It should be preferably done as early as possible after birth, as the long-term neurocognitive prognosis after HSCT is predominantly determined by the degree of damage to the central nervous system at time of transplant (31). 


\subsection{Supportive symptom-based treatments}

Coordinated by an experienced physician, a comprehensive team of specialists such as rheumatologists, physiotherapists, occupational therapists, orthopaedic surgeons, neurosurgeons, cardiologists, pneumologists and otorhinolaryngologists are necessary to address the many potential comorbidities of these progressive diseases (43) (Table 3). The role of the rheumatologist is essential for information, pain-relief (painkillers prescription, local corticosteroids infiltrations), physical therapy supervision, and discussion of the indications of surgery with orthopaedic colleagues. Of importance, patients with MPS are in general at high risk of anaesthetic and surgical complications because of airway compromise due to GAG accumulation, enlarged tongue, odontoid dysplasia and spinal instability, susceptibility to respiratory infections, restrictive lung disease and cardiac disease $(31,56)$. Hence, general anaesthesia should be avoided if possible, and when unavoidable, it should be done by an anaesthesiologist with MPS experience $(31,43,44)$. It is also important to be aware of the considerable psychosocial burden of these chronic, debilitating and progressive conditions. Patients with MPS experience great deterioration of their quality of life (57). Many of them exhibit psychological symptoms which may currently be overlooked during treatment of physical disease manifestations (58). Hence, a psychological evaluation and support is recommended, especially in patients with milder forms, in whom intelligence is typically preserved and whose psychological health worsens because they understand their disease predicament more fully (59). Social workers may be helpful to overcome social insecurity and unemployment $(44,57)$. Finally, patient associations may provide invaluable networking opportunities for patients and families to share information and connect with others experiencing the same challenges $(43,44)$.

\section{Conclusion}

Even if MPS are rare, they are underestimated and rheumatologists are probably not aware enough of their existence. In addition to the typical severe forms associated with markedly decreased survival, milder musculoskeletal-prevailing forms that may escape diagnosis until adulthood exist. Thus, the rheumatologist may sometimes be the first physician to consider the diagnosis, especially in front of symptoms such as joint pain, stiffness, dysmorphic features associated with dysostosis multiplex on X-rays. Making the diagnosis as soon as possible is essential, because substitutive enzyme therapy is available for some MPS. Given early, it might stop 
or slow down the development of tissue damage, which is unfortunately irreversible. The management of MPS should be multidisciplinary, led by an experienced physician in a reference centre, and the contribution of the rheumatologist is important to ensure symptom control and prevent complications.

\section{Conflicts of interest}

None of the authors has any conflicts of interest to declare. 


\section{References}

1. Lehman TJA, Miller N, Norquist B, Underhill L, Keutzer J. Diagnosis of the mucopolysaccharidoses. Rheumatol Oxf Engl. 2011;50 Suppl 5:v41-48.

2. Cimaz R, La Torre F. Mucopolysaccharidoses. Curr Rheumatol Rep. 2014;16(1):389.

3. Prat C, Lemaire O, Bret J, Zabraniecki L, Fournié B. Morquio syndrome: diagnosis in an adult. Jt Bone Spine Rev Rhum. 2008;75(4):495-8.

4. Bruni S, Lavery C, Broomfield A. The diagnostic journey of patients with mucopolysaccharidosis I: A real-world survey of patient and physician experiences. Mol Genet Metab Rep. 2016;8:67-73.

5. Vijay S, Wraith JE. Clinical presentation and follow-up of patients with the attenuated phenotype of mucopolysaccharidosis type I. Acta Paediatr Oslo Nor 1992. 2005;94(7):872-7.

6. Coppa GV. Why should rheumatologists be aware of the mucopolysaccharidoses? Rheumatol Oxf Engl. 2011;50 Suppl 5:v1-3.

7. Clarke LA. Pathogenesis of skeletal and connective tissue involvement in the mucopolysaccharidoses: glycosaminoglycan storage is merely the instigator. Rheumatol Oxf Engl. 2011;50 Suppl 5:v13-18.

8. Opoka-Winiarska V, Jurecka A, Emeryk A, Tylki-Szymańska A. Osteoimmunology in mucopolysaccharidoses type I, II, VI and VII. Immunological regulation of the osteoarticular system in the course of metabolic inflammation. Osteoarthritis Cartilage. 2013;21(12):181323.

9. Simonaro CM, Ge Y, Eliyahu E, He X, Jepsen KJ, Schuchman EH. Involvement of the Tolllike receptor 4 pathway and use of TNF-alpha antagonists for treatment of the mucopolysaccharidoses. Proc Natl Acad Sci U S A. 2010;107(1):222-7.

10. Simonaro CM, Haskins ME, Schuchman EH. Articular chondrocytes from animals with a dermatan sulfate storage disease undergo a high rate of apoptosis and release nitric oxide and inflammatory cytokines: a possible mechanism underlying degenerative joint disease in the mucopolysaccharidoses. Lab Investig J Tech Methods Pathol. 2001;81(9):1319-28.

11. De Franceschi L, Roseti L, Desando G, Facchini A, Grigolo B. A molecular and histological characterization of cartilage from patients with Morquio syndrome. Osteoarthritis Cartilage. 2007;15(11):1311-7.

12. Bouzidi H, Khedhiri S, Laradi S, Ferchichi S, Daudon M, Miled A. [Mucopolysaccharidosis IVA (Morquio A syndrome): clinical, biological and therapeutic aspects]. Ann Biol Clin (Paris). 2007;65(1):5-11.

13. Meikle PJ, Hopwood JJ, Clague AE, Carey WF. Prevalence of lysosomal storage disorders. JAMA. 1999;281(3):249-54.

14. da Rocha Siqueira TC, de Souza CFM, Lompa P, Picarelli M, Scheibel I, Bender F, et al. Screening for Attenuated Forms of Mucopolysaccharidoses in Patients with Osteoarticular Problems of Unknown Etiology. JIMD Rep. 2016;26:99-102. 
15. Nelson J. Incidence of the mucopolysaccharidoses in Northern Ireland. Hum Genet. 1997;101(3):355-8.

16. Nelson J, Crowhurst J, Carey B, Greed L. Incidence of the mucopolysaccharidoses in Western Australia. Am J Med Genet A. 2003;123A(3):310-3.

17. Malm G, Lund AM, Månsson J-E, Heiberg A. Mucopolysaccharidoses in the Scandinavian countries: incidence and prevalence. Acta Paediatr Oslo Nor 1992. 2008;97(11):1577-81.

18. Muenzer J. Overview of the mucopolysaccharidoses. Rheumatol Oxf Engl. $2011 ; 50$ Suppl 5:v4-12.

19. Leadley RM, Lang S, Misso K, Bekkering T, Ross J, Akiyama T, et al. A systematic review of the prevalence of Morquio A syndrome: challenges for study reporting in rare diseases. Orphanet J Rare Dis. 2014 ;9:173.

20. Cimaz R, Coppa GV, Koné-Paut I, Link B, Pastores GM, Elorduy MR, et al. Joint contractures in the absence of inflammation may indicate mucopolysaccharidosis. Pediatr Rheumatol Online J. $2009 ; 7: 18$.

21. Montaño AM, Tomatsu S, Gottesman GS, Smith M, Orii T. International Morquio A Registry: clinical manifestation and natural course of Morquio A disease. J Inherit Metab Dis. 2007 ;30(2):165-74.

22. Morishita K, Petty RE. Musculoskeletal manifestations of mucopolysaccharidoses. Rheumatol Oxf Engl. 2011;50 Suppl 5:v19-25.

23. Silveri CP, Kaplan FS, Fallon MD, Bayever E, August CS. Hurler syndrome with special reference to histologic abnormalities of the growth plate. Clin Orthop. 1991;(269):305-11.

24. White KK. Orthopaedic aspects of mucopolysaccharidoses. Rheumatol Oxf Engl. 2011;50 Suppl 5:v26-33.

25. Aldenhoven M, Sakkers RJB, Boelens J, de Koning TJ, Wulffraat NM. Musculoskeletal manifestations of lysosomal storage disorders. Ann Rheum Dis. 2009;68(11):1659-65.

26. Kahn MF. Chondrodysplasic rheumatism. Br J Rheumatol. 1998;37(8):917.

27. Bouvet JP, Henrard JC, Siaud JR, Paolaggi JB, Auquier L. [Apparently inflammatory early degenerative polyarthropathy]. Rev Rhum Mal Osteoartic. 1974 ;41(2):123-34.

28. Rutten M, Ciet P, van den Biggelaar R, Oussoren E, Langendonk JG, van der Ploeg AT, et al. Severe tracheal and bronchial collapse in adults with type II mucopolysaccharidosis. Orphanet J Rare Dis. 2016 ;11:50.

29. Martin R, Beck M, Eng C, Giugliani R, Harmatz P, Muñoz V, et al. Recognition and diagnosis of mucopolysaccharidosis II (Hunter syndrome). Pediatrics. 2008 Feb;121(2):e377-386.

30. Schiro JA, Mallory SB, Demmer L, Dowton SB, Luke MC. Grouped papules in Hurler-Scheie syndrome. J Am Acad Dermatol. 1996;35(5 Pt 2):868-70.

31. Mitchell J, Berger KI, Borgo A, Braunlin EA, Burton BK, Ghotme KA, et al. Unique medical issues in adult patients with mucopolysaccharidoses. Eur J Intern Med. 2016;34:2-10. 
32. James RA, Singh-Grewal D, Lee S-J, McGill J, Adib N, Australian Paediatric Rheumatology Group. Lysosomal storage disorders: A review of the musculoskeletal features. J Paediatr Child Health. 2016;52(3):262-71.

33. Manger B, Mengel E, Schaefer RM. Rheumatologic aspects of lysosomal storage diseases. Clin Rheumatol. 2007;26(3):335-41.

34. Mendelsohn NJ, Wood T, Olson RA, Temme R, Hale S, Zhang H, et al. Spondyloepiphyseal dysplasias and bilateral legg-calvé-perthes disease: diagnostic considerations for mucopolysaccharidoses. JIMD Rep. 2013;11:125-32.

35. Mahalingam K, Janani S, Priya S, Elango EM, Sundari RM. Diagnosis of mucopolysaccharidoses: how to avoid false positives and false negatives. Indian J Pediatr. 2004;71(1):29-32.

36. Gallegos-Arreola MP, Machorro-Lazo MV, Flores-Martínez SE, Zúñiga-González GM, Figuera LE, González-Noriega A, et al. Urinary glycosaminoglycan excretion in healthy subjects and in patients with mucopolysaccharidoses. Arch Med Res. 2000;31(5):505-10.

37. Piraud M, Boyer S, Mathieu M, Maire I. Diagnosis of mucopolysaccharidoses in a clinically selected population by urinary glycosaminoglycan analysis: a study of 2,000 urine samples. Clin Chim Acta Int J Clin Chem. 1993 ;221(1-2):171-81.

38. Auray-Blais C, Lavoie P, Tomatsu S, Valayannopoulos V, Mitchell JJ, Raiman J, et al. UPLCMS/MS detection of disaccharides derived from glycosaminoglycans as biomarkers of mucopolysaccharidoses. Anal Chim Acta. 2016 ;936:139-48.

39. Cozma C, Eichler S, Wittmann G, Flores Bonet A, Kramp GJ, Giese A-K, et al. Diagnosis of Morquio Syndrome in Dried Blood Spots Based on a New MRM-MS Assay. PloS One. 2015;10(7):e0131228.

40. Terlato NJ, Cox GF. Can mucopolysaccharidosis type I disease severity be predicted based on a patient's genotype? A comprehensive review of the literature. Genet Med Off J Am Coll Med Genet. $2003 ; 5(4): 286-94$.

41. Tomatsu S, Montaño AM, Nishioka T, Gutierrez MA, Peña OM, Tranda Firescu GG, et al. Mutation and polymorphism spectrum of the GALNS gene in mucopolysaccharidosis IVA (Morquio A). Hum Mutat. 2005 ;26(6):500-12.

42. Akella RRD, Kadali S. Amniotic fluid glycosaminoglycans in the prenatal diagnosis of mucopolysaccharidoses - A useful biomarker. Clin Chim Acta Int J Clin Chem. 2016 ;460:636.

43. Valayannopoulos V, Wijburg FA. Therapy for the mucopolysaccharidoses. Rheumatol Oxf Engl. 2011;50 Suppl 5:v49-59.

44. Protocole National de Diagnostic et de Soins (PNDS) sur les mucopolysaccharidoses. Filières de Santé Maladies Rares. G2M, Groupement Maladies Héréditaires du Métabolisme. Juillet 2016. http://www.hassante.fr/portail/plugins/ModuleXitiKLEE/types/FileDocument/doXiti.jsp?id=c_2659923

45. Beck M, Arn P, Giugliani R, Muenzer J, Okuyama T, Taylor J, et al. The natural history of MPS I: global perspectives from the MPS I Registry. Genet Med Off J Am Coll Med Genet. 
$2014 ; 16(10): 759-65$.

46. Gabrielli O, Clarke LA, Ficcadenti A, Santoro L, Zampini L, Volpi N, et al. 12 year follow up of enzyme-replacement therapy in two siblings with attenuated mucopolysaccharidosis I: the important role of early treatment. BMC Med Genet. 2016 ;17:19.

47. Gilkes JA, Heldermon CD. Mucopolysaccharidosis III (Sanfilippo Syndrome)- disease presentation and experimental therapies. Pediatr Endocrinol Rev PER. 2014;12 Suppl 1:13340 .

48. Sands MS. Mucopolysaccharidosis type VII: A powerful experimental system and therapeutic challenge. Pediatr Endocrinol Rev PER. 2014;12 Suppl 1:159-65.

49. Wraith JE, Clarke LA, Beck M, Kolodny EH, Pastores GM, Muenzer J, et al. Enzyme replacement therapy for mucopolysaccharidosis I: a randomized, double-blinded, placebocontrolled, multinational study of recombinant human alpha-L-iduronidase (laronidase). $\mathbf{J}$ Pediatr. 2004 ;144(5):581-8.

50. Burton BK, Berger KI, Lewis GD, Tarnopolsky M, Treadwell M, Mitchell JJ, et al. Safety and physiological effects of two different doses of elosulfase alfa in patients with morquio a syndrome: A randomized, double-blind, pilot study. Am J Med Genet A. 2015;167A(10):227281.

51. Tomatsu S, Sawamoto K, Shimada T, Bober MB, Kubaski F, Yasuda E, et al. Enzyme replacement therapy for treating mucopolysaccharidosis type IVA (Morquio A syndrome): effect and limitations. Expert Opin Orphan Drugs. 2015;3(11):1279-90.

52. Harmatz P, Giugliani R, Schwartz I, Guffon N, Teles EL, Miranda MCS, et al. Enzyme replacement therapy for mucopolysaccharidosis VI: a phase 3, randomized, double-blind, placebo-controlled, multinational study of recombinant human $\mathrm{N}$-acetylgalactosamine 4sulfatase (recombinant human arylsulfatase B or rhASB) and follow-on, open-label extension study. J Pediatr. 2006;148(4):533-9.

53. Braunlin E, Rosenfeld H, Kampmann C, Johnson J, Beck M, Giugliani R, et al. Enzyme replacement therapy for mucopolysaccharidosis VI: long-term cardiac effects of galsulfase (Naglazyme®) therapy. J Inherit Metab Dis. 2013;36(2):385-94.

54. Clarke LA, Wraith JE, Beck M, Kolodny EH, Pastores GM, Muenzer J, et al. Long-term efficacy and safety of laronidase in the treatment of mucopolysaccharidosis I. Pediatrics. 2009;123(1):229-40.

55. Aldenhoven M, Wynn RF, Orchard PJ, O’Meara A, Veys P, Fischer A, et al. Long-term outcome of Hurler syndrome patients after hematopoietic cell transplantation: an international multicenter study. Blood. $2015 ; 125(13): 2164-72$.

56. Walker RW, Darowski M, Morris P, Wraith JE. Anaesthesia and mucopolysaccharidoses. A review of airway problems in children. Anaesthesia. 1994 ;49(12):1078-84.

57. Hendriksz CJ, Berger KI, Lampe C, Kircher SG, Orchard PJ, Southall R, et al. Health-related quality of life in mucopolysaccharidosis: looking beyond biomedical issues. Orphanet J Rare Dis. 2016 ;11(1):119.

58. Ali N, Cagle S. Psychological health in adults with morquio syndrome. JIMD Rep. 
2015;20:87-93.

1

2

3

4

5

6

7

8

9

10

11

12

13

14

15

16

17

18

19

20

21

22

23

24

25

26

27

28

29

30

31

32

33

34

35

36

37

38

39

40

41

42

43

44

45

46

47

48

49

50

51

52

53

54

55

56

57

58

59

60

61

62

63

64

65

59. Kuratsubo I, Suzuki Y, Orii KO, Kato T, Orii T, Kondo N. Psychological status of patients with mucopolysaccharidosis type II and their parents. Pediatr Int Off J Jpn Pediatr Soc. 2009 ;51(1):41-7. 
Table 1: Mucopolysaccharidosis (MPS) classification. There are 11 known enzymes that give rise to 7 distinct MPS (MPS V and VIII are no longer used). Most of MPS have autosomal recessive transmission, except MPS II, which is X-linked recessive. An enzyme replacement therapy (recombinant deficient enzyme) is now available for four of them, and in development for two more. The multiplicity of the enzymes involved in GAGs catabolism and their deficiency account for the numerous subtypes of MPS, but also for the great clinical heterogeneity and various phenotypes inside each subtype. For instance, different mutations of a same enzyme, $\alpha$-Liduronidase, will either lead to a very severe phenotype called Hurler syndrome, an intermediary severe phenotype (Hurler-Scheie), and a much less severe phenotype (Scheie) in the MPS I subtype. Milder forms more at risk to be later diagnosed in adults are more likely to be found in the subtypes of MPS type I (Scheie syndrome), IV, VI and VII. Other types concern almost exclusively infantile diseases with a much shorter life span. The forms which are more likely encountered by adult rheumatologists are types IVA (also called Morquio A syndrome), VI (Maroteaux-Lamy) and VII (Sly) which are typically the forms where osteoarticular manifestations prevail, with usually no intellectual deficit, and where visceral injuries are less frequently present.

\begin{tabular}{|c|c|c|c|c|c|c|c|}
\hline Type & Name & Impaired enzyme & $\begin{array}{c}\text { GAG } \\
\text { storage } \\
\text { material }\end{array}$ & $\begin{array}{c}\text { Gene } \\
\text { name and } \\
\text { location }\end{array}$ & Transmission & $\begin{array}{c}\text { Incidence } \\
(1 / 100,000 \\
\text { live } \\
\text { births })\end{array}$ & $\begin{array}{c}\text { Enzyme } \\
\text { replacement } \\
\text { therapy }\end{array}$ \\
\hline MPS I & $\begin{array}{l}\text { Hurler, } \\
\text { Scheie, or } \\
\text { Hurler- } \\
\text { Scheie } \\
\text { syndromes }\end{array}$ & $\alpha$-L-Iduronidase & $\begin{array}{l}\text { DS and } \\
\text { HS }\end{array}$ & $\begin{array}{l}\text { IDUA } \\
4 \mathrm{p} 16.3\end{array}$ & $\begin{array}{l}\text { Autosomal } \\
\text { recessive }\end{array}$ & $0.69-1.66$ & 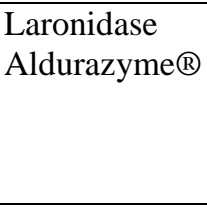 \\
\hline MPS II & $\begin{array}{l}\text { Hunter } \\
\text { syndrome }\end{array}$ & $\begin{array}{l}\text { Iduronate-2- } \\
\text { sulfatase }\end{array}$ & $\begin{array}{l}\text { DS and } \\
\text { HS }\end{array}$ & $\begin{array}{l}\text { IDS } \\
\text { Xq28 }\end{array}$ & $\begin{array}{l}\text { X-linked } \\
\text { recessive* }\end{array}$ & $0.3-0.71$ & $\begin{array}{l}\text { Idursulfase } \\
\text { Elaprase } ®\end{array}$ \\
\hline MPS IIIA & $\begin{array}{l}\text { Sanfilippo A } \\
\text { syndrome }\end{array}$ & $\begin{array}{l}\text { Heparan-N- } \\
\text { sulfatase }\end{array}$ & HS & $\begin{array}{l}\text { SGSH } \\
17 q 25.3\end{array}$ & $\begin{array}{l}\text { Autosomal } \\
\text { recessive }\end{array}$ & $0.29-1.89$ & $\begin{array}{l}\text { In } \\
\text { development }\end{array}$ \\
\hline MPS IIIB & $\begin{array}{l}\text { Sanfilippo B } \\
\text { syndrome }\end{array}$ & $\begin{array}{l}\alpha-\mathrm{N}- \\
\text { acetylglucosaminid } \\
\text { ase }\end{array}$ & HS & $\begin{array}{l}\text { NAGLU } \\
17 q 21\end{array}$ & $\begin{array}{l}\text { Autosomal } \\
\text { recessive }\end{array}$ & $0.42-0.72$ & \\
\hline MPS IIIC & $\begin{array}{l}\text { Sanfilippo C } \\
\text { syndrome }\end{array}$ & $\begin{array}{l}\text { AcetylCoA } \alpha- \\
\text { glucosamine } \\
\text { acetyltransferase }\end{array}$ & HS & $\begin{array}{l}\text { HGSNAT } \\
8 \mathrm{p} 11.1\end{array}$ & $\begin{array}{l}\text { Autosomal } \\
\text { recessive }\end{array}$ & $0.07-0.21$ & \\
\hline MPS IIID & $\begin{array}{l}\text { Sanfilippo D } \\
\text { syndrome }\end{array}$ & $\begin{array}{l}\mathrm{N}- \\
\text { acetylglucosamine } \\
\text { 6-sulfatase }\end{array}$ & HS & $\begin{array}{l}\text { GNS } \\
12 q 14\end{array}$ & $\begin{array}{l}\text { Autosomal } \\
\text { recessive }\end{array}$ & 0.1 & \\
\hline $\begin{array}{l}\text { MPS } \\
\text { IVA }\end{array}$ & $\begin{array}{l}\text { Morquio A } \\
\text { syndrome }\end{array}$ & $\begin{array}{l}\text { Galactosamine-6- } \\
\text { sulfate sulfatase }\end{array}$ & $\begin{array}{l}\mathrm{KS} \text { and } \\
\mathrm{CS}\end{array}$ & $\begin{array}{l}\text { GALNS } \\
16 q 24.3\end{array}$ & $\begin{array}{l}\text { Autosomal } \\
\text { recessive }\end{array}$ & $0.22-1.3$ & $\begin{array}{l}\text { Elosulfase } \\
\text { alpha } \\
\text { Vimizim® }\end{array}$ \\
\hline MPS IVB & $\begin{array}{l}\text { Morquio B } \\
\text { syndrome }\end{array}$ & $\beta$-galactosidase & $\mathrm{KS}$ & $\begin{array}{l}\text { GLB1 } \\
3 \mathrm{p} 21.33\end{array}$ & $\begin{array}{l}\text { Autosomal } \\
\text { recessive }\end{array}$ & $0.02-0.14$ & \\
\hline MPS VI & $\begin{array}{l}\text { Maroteaux- } \\
\text { Lamy } \\
\text { syndrome }\end{array}$ & Arylsulfatase B & $\mathrm{DS}$ & $\begin{array}{l}\text { ARSB } \\
5 q 11 . q 13\end{array}$ & $\begin{array}{l}\text { Autosomal } \\
\text { recessive }\end{array}$ & $0.36-1.3$ & $\begin{array}{l}\text { Galsulfase } \\
\text { Nalgazyme } ®\end{array}$ \\
\hline MPS VII & $\begin{array}{l}\text { Sly } \\
\text { syndrome }\end{array}$ & $\beta$-glucuronidase & $\begin{array}{l}\text { DS, HS } \\
\text { and CS }\end{array}$ & $\begin{array}{l}\text { GUSB } \\
7 \mathrm{q} 21.11\end{array}$ & $\begin{array}{l}\text { Autosomal } \\
\text { recessive }\end{array}$ & $0.05-0.29$ & $\begin{array}{l}\text { In } \\
\text { development }\end{array}$ \\
\hline MPS IX & $\begin{array}{l}\text { Natowicz } \\
\text { syndrome }\end{array}$ & Hyaluronidase I & HA & $\begin{array}{l}\mathrm{AH} \\
3 \mathrm{p} 21.3- \\
\mathrm{p} 21.2\end{array}$ & $\begin{array}{l}\text { Autosomal } \\
\text { recessive }\end{array}$ & $<0.01$ & \\
\hline
\end{tabular}

*Most patients are male

GAG, glycosaminoglycan; DS, dermatan suflate; HS, heparan sulfate; KS, keratan sulfate; CS, chondroitin sulfate; HA, hyaluronic acid or hyaluronan. 
Table 2. Mechanisms of bone and joint disease in the MPS (adapted from (7))

\begin{tabular}{|l|l|}
\hline \multicolumn{1}{|c|}{ Articular cartilage } & \multicolumn{1}{|c|}{ Growth plate } \\
\hline - GAG deposition & - GAG deposition \\
\hline - Enhanced chondrocyte apoptosis & - Altered growth plate morphology \\
\hline - Increased nitric oxide production & - Altered trabecular architecture \\
\hline $\begin{array}{l}\text { Increased cytokine and chemokine } \\
\text { production }\end{array}$ & - Osteoclast dysfunction \\
\hline - Macrophage recruitment & - $\begin{array}{l}\text { Inhibition of collagenase activity of } \\
\text { cathepsin K }\end{array}$ \\
\hline - Activation of the TLR4 pathway & - Alteration of STAT pathway \\
\hline - Increased MMPs, TNF- $\alpha$ & - Decreased IL-6 and IL-6 family chemokines \\
\hline
\end{tabular}

GAG, glycosaminoclycan; TLR4, Toll-Like Receptor 4; MMPs, matrix metallopeptidase; TNF- $\alpha$, Tumour Necrosis Factor $\alpha$; STAT, signal transducer and activator of transcription; IL-6, interleukine 6 
Table 3: Potential multisystemic symptoms that may be observed in mucopolysaccharidosis (not exhaustive list).

\begin{tabular}{|c|c|}
\hline \multirow[t]{6}{*}{ Osteo-articular } & $\begin{array}{l}\text { Joint stiffness (except in Morquio syndrome*: joint hypermobility of the } \\
\text { distal joints contrasting with proximal stiffness) }\end{array}$ \\
\hline & Joint limitation \\
\hline & Joint contracture \\
\hline & $\begin{array}{ll}\begin{array}{l}\text { Dysmorphic features, } \\
\text { Osteochondrodysplasia, } \\
\text { Dysostosis multiplex }\end{array} & \begin{array}{l}\text { Height variation (from dwarfism to near-normal) } \\
\text { kyphosis, odontoid dysplasia } \\
\text { Hip dysplasia, genu valgum, flat feet } \\
\text { Dysostogenesis, spondyloepyphyseal dysplasia, } \\
\text { spondylometaphyseal dysplasia, platyspondylia }\end{array}\end{array}$ \\
\hline & Stiffness, chondrodysplasic rheumatism $* *$ \\
\hline & $\begin{array}{l}\text { Entrapment neuropathy (mainly carpal tunnel } \\
\text { syndrome), trigger digits, claw hands (phalangeal } \\
\text { contracture) }\end{array}$ \\
\hline Dysmorphia & $\begin{array}{l}\text { Coarse facies (large nostrils, thick lips and ears, macroglossia, thick hair) } \\
\text { Organomegaly }\end{array}$ \\
\hline Neurological & $\begin{array}{l}\text { Psychomotor retardation, behaviour trouble, central impairment, peripheral } \\
\text { compression, hydrocephalus, compression of the cervical spinal cord } \\
\text { (hypoplasia of the dens and atlantoaxial instability) }\end{array}$ \\
\hline Cardiological & Valve disease, myocardial infiltration, coronary heart disease \\
\hline Respiratory & Tracheal and bronchial collapse, restrictive pulmonary disease ${ }^{* * *}$ \\
\hline $\begin{array}{l}\text { Ear, nose and } \\
\text { throat/stomatological }\end{array}$ & $\begin{array}{l}\text { Macroglossia, tonsils' hypertrophia, perception deafness, otitis media, } \\
\text { recurrent upper tract infections, sleep apnea, dental colorations and gum } \\
\text { recession }\end{array}$ \\
\hline Ophtalmological & Lens opacity, corneal clouding, retinopathy, blindness \\
\hline Digestive & Inguinal and/or umbilical hernias, hepatomegaly \\
\hline Dermatological & Thickened and rough skin texture $\dagger$, pebbly papulest \\
\hline
\end{tabular}

*Also known as MPS type IV; ** Acute "osteoarthrititic-like" exacerbations in patients with epyphyseal dysplasia, with swollen joints and synovitis, but with mechanic synovial fluid and without any elevation of acute phase reactants $(26,27)$; ***Due to spinal deformations (28); $\dagger$ Overall skin texture in patients with MPS can be thickened and rough. $\$$ MPS II (29), and rarely MPS I (30) can be associated with a distinctive skin lesion consisting of white "pebbly" papules 2$10 \mathrm{~mm}$ in diameter, sometimes coalescing in ridges. 
Table 4. Differential diagnoses and common misdiagnoses for MPS based on joint and bone symptoms

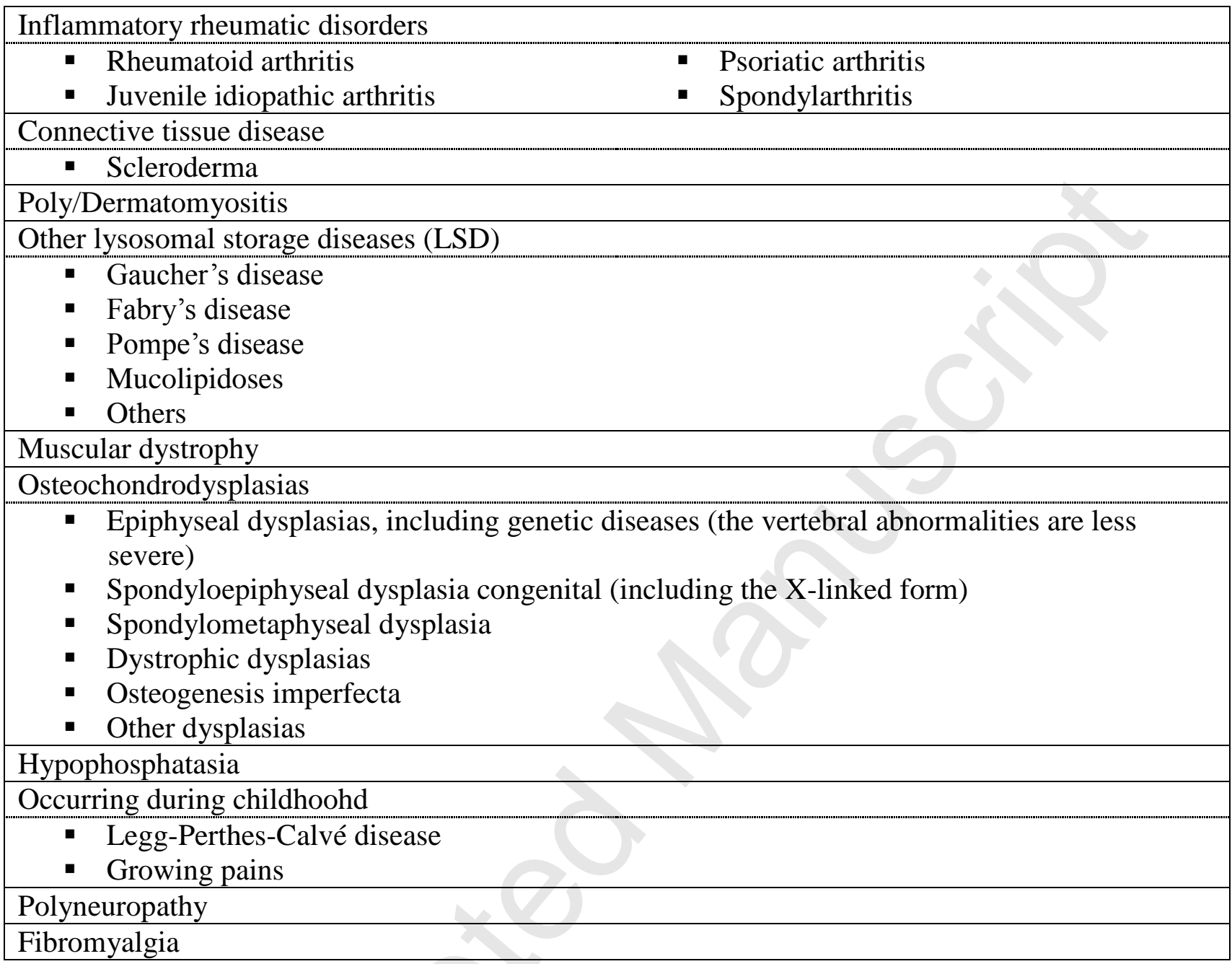


Figure 1. Mucopolysaccharidosis (MPS) type IVA (Morquio syndrome) with spondyloepiphyseal dysplasia diagnosed in a 52-year adult. The patient had previously been diagnosed with psoriatic arthritis sine psoriasis at the age of 37, and had received methotrexate and etanercept (with no clinical efficacy) before the final diagnosis of MPS IVA was made 15 years later. In his medical history, symptoms had started in the adolescence, and he had been diagnosed with bilateral "osteochondritis" at the age of 10 and 13, and had consequently received two hip total arthroplasties at the age of 28 and 29. Elevated acute phase reactants were detected during the first years of follow-up, considered related to a pilonidal cyst, and were no longer observed after its removal. Immunological markers (rheumatoid factor, anti-citrullinated protein antibodies, antinuclear antibodies) were absent. Note the metacarpophalangeal hooks, hands and feet epiphyseal dysplasia, kyphoscoliosis and platyspondylia, and the dysmorphic morphological facial features, with a large and short neck. The misdiagnosis with psoriatic arthritis was linked to chondrodysplasic rheumatism, responsible for clinical and ultrasonographic synovitis and destruction of the carpa, the right elbow and the shoulders. However, joint aspiration found an aseptic mechanical fluid with no crystal.

Figure 2. Diagnostic algorithm for attenuated mycopolysaccharidoses (adapted from [1, 20]). ${ }^{+}$Newborn infants with MPS, although normal appearing, often have radiological evidence of bone and joint abnormalities. ${ }^{\ddagger}$ Overall skin texture in patients with MPS can be thickened and rough. RA, rheumatoid arthritis; JIA, juvenile idiopathic arthritis; ESR, erythrocyte sedimentation rate; CRP, C-reactive protein; ANA, antinuclear antibodies; NSAIDs, nonsteroidal anti-inflammatory drugs; MPS, mucopolysaccharidosis; GAGs, glycosmaminoglycans. 


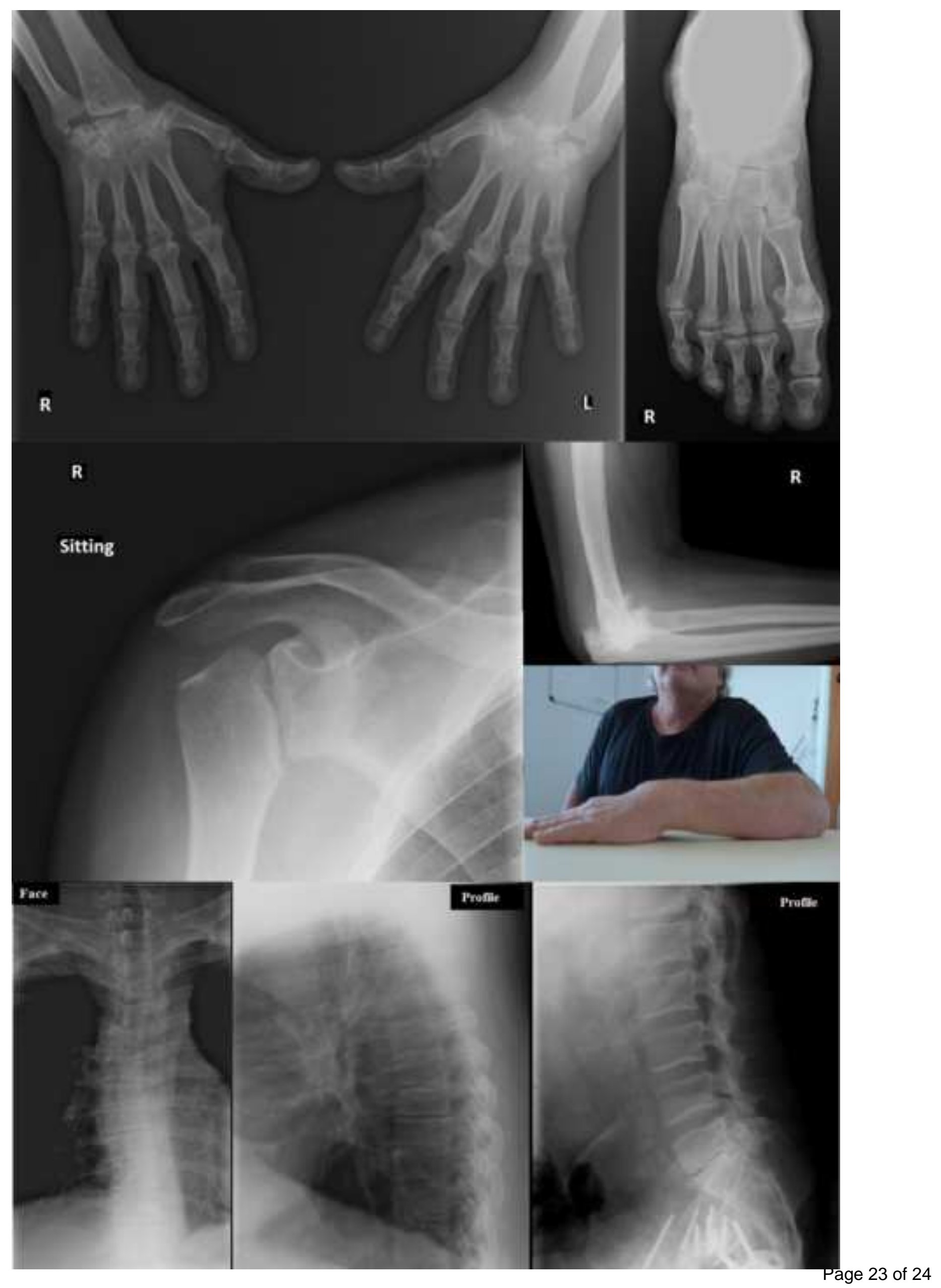

R

R

Sitting

Fane
Profilt

rage 23 of 24

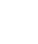


